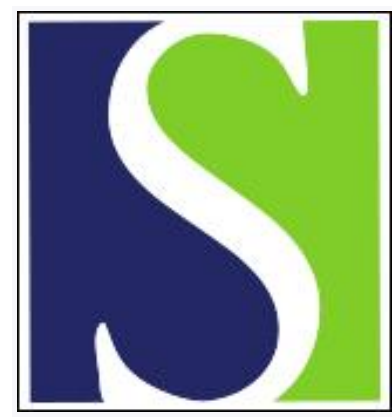

Scand J Work Environ Health 2015;41(2):153-163

https://doi.org/10.5271/sjweh.3479

Published online: 18 Jan 2015, Issue date: 01 Mar 2015

Effect of workplace- versus home-based physical exercise on musculoskeletal pain among healthcare workers: a cluster randomized controlled trial

by Jakobsen MD, Sundstrup E, Brandt M, Jay K, Aagaard P, Andersen LL

Physical exercise at work together with colleagues is more effective than home-based exercise in reducing musculoskeletal pain and use of analgesics among female healthcare workers.

Affiliation: National Research Centre for the Working Environment, Lersø Parkalle 105, Copenhagen, Denmark. markusdue@gmail.dk

Refers to the following texts of the Journal: $2014 ; 40(1): 74-81$

2012;38(2):183-184 2012;38(2):182 2011;37(3):196-203

2008;34(1):55-65

The following articles refer to this text: $2016 ; 42(6): 510-519$; 2018;44(2):134-146; 2018;44(6):568-584; 2020;46(1):1-4

Key terms: back pain; cluster randomized controlled trial; healthcare; healthcare worker; MSD; musculoskeletal disorder; musculoskeletal pain; neck pain; occupational health; occupational health; physical exercise; randomized controlled trial; shoulder pain; strength training; workplace

This article in PubMed: www.ncbi.nlm.nih.gov/pubmed/25596848

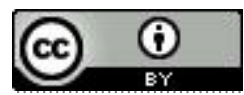




\title{
Effect of workplace- versus home-based physical exercise on musculoskeletal pain among healthcare workers: a cluster randomized controlled trial
}

\author{
by Markus D Jakobsen, MSc, , 2 Emil Sundstrup, MSc, , 2 Mikkel Brandt, MSc, , , 3 Kenneth Jay, MSc, , , , 4 \\ Per Aagaard, PhD, ${ }^{2}$ Lars L Andersen, $P h D^{1}$
}

\begin{abstract}
Jakobsen MD, Sundstrup E, Brandt M, Jay K, Aagaard P, Andersen LL. Effect of workplace- versus home-based physical exercise on musculoskeletal pain among healthcare workers: a cluster randomized controlled trial. Scand J Work Environ Health. 2015;41(2):153-163. doi:10.5271/sjweh.3479
\end{abstract}

Objective Numerous studies has shown that regular physical exercise can reduce musculoskeletal pain, but
the optimal setting to achieve high adherence and effectiveness remains unknown. This study investigated the
effect of workplace versus home-based physical exercise on musculoskeletal pain among healthcare workers.
Methods The randomized controlled trial (RCT) comprised 200 female healthcare workers from 18 departments at
3 hospitals. Participants were randomly allocated at the cluster level to ten weeks of: (i) workplace physical exercise
(WORK) performed during working hours for $5 \times 10$ minutes per week and up to 5 group-based coaching sessions
on motivation for regular physical exercise, or (ii) home-based physical exercise (HOME) performed during leisure
time for $5 \times 10$ minutes per week. Both groups received ergonomic counseling on patient handling and use of lifting
aides. Average pain intensity ( $0-10$ scale) in the low back and neck/shoulder was the primary outcome.

Results Per week, 2.2 (SD 1.1) and 1.0 (SD 1.2) training sessions were performed in WORK and HOME groups, respectively. Pain intensity, back muscle strength and use of analgesics improved more following WORK than HOME $(\mathrm{P}<0.05)$. Between-group differences at follow-up (WORK versus HOME) was -0.7 points for pain intensity [ $95 \%$ confidence interval $(95 \% \mathrm{CI})-1.0--0.3], 5.5 \mathrm{Nm}$ for back muscle strength $(95 \% \mathrm{CI} 2.0-9.0)$, and -0.4 days per week for use of analgesics $(95 \% \mathrm{CI}-0.7-0.2)$. The effect size for between-group differences in pain intensity was small (Cohen's $\mathrm{d}=0.31$ ).

Conclusions Workplace physical exercise is more effective than home-based exercise in reducing musculoskeletal pain, increasing muscle strength and reducing the use of analgesics among healthcare workers.

Key terms back pain; healthcare; musculoskeletal disorder; MSD; neck pain; occupational health; shoulder pain; strength training.

Musculoskeletal disorders (MSD) can have individual consequences in terms of impaired physical function and quality of life, as well as socioeconomic consequences in terms of reduced work ability, increased sickness absence, and premature exit from the labor market (1, 2). A high prevalence of MSD (3) and long-term sickness absence (4) have been reported in occupations with physically demanding work. Healthcare workers frequently perform patient handling, which involves known risk factors for MSD such as awkward postures and high biomechanical loading of the back (5). Accord- ingly, among a population of 8000 Danish healthcare workers, $28 \%$ and $23 \%$ reported chronic pain in the neck/shoulders and lower back, respectively (6). The emerging global shortage in the healthcare workforce (7) highlights the importance of sustaining good musculoskeletal health among healthcare workers.

Although implementation of assistive devices and adequate training, supervision and manual handling techniques have increased the preventive efforts in the Danish healthcare sector, the incidence of MSD remain high (8). Thus, single strategy ergonomic interventions

\footnotetext{
1 National Research Centre for the Working Environment, Copenhagen, Denmark.

2 Department of Sports Science and Clinical Biomechanics, SDU Muscle Research Cluster, University of Southern Denmark, Odense, Denmark.

3 Center for Sensory-Motor Interaction (SMI), Department of Health Science and Technology, Aalborg University, Denmark.

4 Electronics and Computer Science, Faculty of Physical and Applied Sciences, University of Southampton, Southampton, UK.
} 
aiming to reduce or prevent work-related MSD seem insufficient $(9,10)$. An additional strategy to reduce the risk of sustaining work-related MSD is to increase the workers physical capacity by physical training. Whereas several studies have reported reduced pain in the neck, shoulder, and low-back regions in response to specific workplace physical exercise interventions targeted at laboratory technicians and office workers (11-13), only limited and contrasting evidence exists among healthcare workers (14). A major problem is that adherence to training in such trials are often low.

Physical exercise at the workplace may be considered costly in terms of working hours spent, purchasing of equipment, and employment of training instructors, which may limit willingness from the management to initiate such activities. Alternatively, encouraging employees to perform leisure-time physical activity by providing exercise equipment and training guidelines may seem as a cost-efficient alternative. However, supervised and group-based intervention protocols seem to enhance exercise adherence, whereas home-based exercise interventions are often met with low adherence $(15,16)$. Accordingly, performing physical exercise at the workplace along with colleagues and exercise instructors may be more motivating for some employees whereas others might be disinclined to exercise with their colleagues at work. In general, employee and management motivation, enhanced through a greater understanding of the physiological and social benefits as well as cost efficiency (in terms of ie, reduced sickness absence), may be primary factors determining the adherence to the training performed.

The aim of the present study was to investigate the effect of workplace versus home-based physical exercise (WORK versus HOME) on musculoskeletal pain in the back and neck/shoulders among healthcare workers. We tested whether we were able to reject the null-hypothesis of no difference between a low-cost home-based intervention among healthcare workers compared with a workplace-based intervention that invests working hours, equipment, and on-site training instructors in reducing musculoskeletal pain.

\section{Methods}

\section{Study design}

A two-armed parallel-group, single-blind, cluster randomized controlled trial (RCT) with allocation concealment was conducted among healthcare workers recruited from three hospitals (18 departments) situated in Copenhagen, Denmark, from August 2013 to January 2014. As each hospital department functions as a separate entity, cluster randomization at the department level was chosen to increase adherence and avoid contamination between interventions. The participants were allocated to a 10 -week intervention period and randomly assigned to either the WORK or HOME group. The Danish National Ethics Committee on Biomedical Research (Ethical committee of Frederiksberg and Copenhagen; H-3-2010-062) approved the study - which is registered in ClinicalTrials.gov (NCT01921764) - prior to enrolment of participants, ensuring the study aim, hypothesis, and primary outcome parameters were pre-defined. The study adhered to the CONSORT checklist to ensure transparent and standardized reporting of the RCT. All experimental conditions conformed to The Declaration of Helsinki. The study protocol has been published elsewhere (17).

\section{Recruitment and flow of participants}

Participant recruitment consisted of a short screening questionnaire in June 2013 followed by a baseline clinical examination and questionnaire in August and September 2013. All participants were informed about the purpose and content of the project and gave their written informed consent to participate in the study.

The screening questionnaire was administered to 490 healthcare workers (aged 18-67 years) from three Danish hospitals. In total 314 replied, of which 275 were interested to participate in the research project. The initial inclusion criteria based on the screening questionnaire were non-pregnant female healthcare workers with no current cardiovascular or other life-threatening diseases. Of the 275 interested respondents, 254 met the above criteria and were invited for a baseline clinical examination, to which 207 showed up. Exclusion criteria of the clinical exam were: (i) hypertension (systolic blood pressure $(\mathrm{BP})>160$, diastolic $\mathrm{BP}>100$ ), (ii) a medical history of cardiovascular diseases (eg, chest pain during physical exercise, heart failure, myocardial infarction and stroke), (iii) a medical history of life threatening disease, or (iv) current pregnancy.

During the baseline clinical examination and questionnaire survey, seven workers were excluded $(\mathrm{N}=200)$ due to contraindications: five due to high blood pressure and two due to blood clot incidence within the last two years. The overall flow of participant enrolment is illustrated in figure 1 .

\section{Randomization and blinding}

On the basis of the questionnaire we randomly allocated the 18 departments (200 participants), using a computer-generated random numbers table, to receive either physical exercise at the worksite or at home. The randomization was performed in SAS (SAS Institute, 


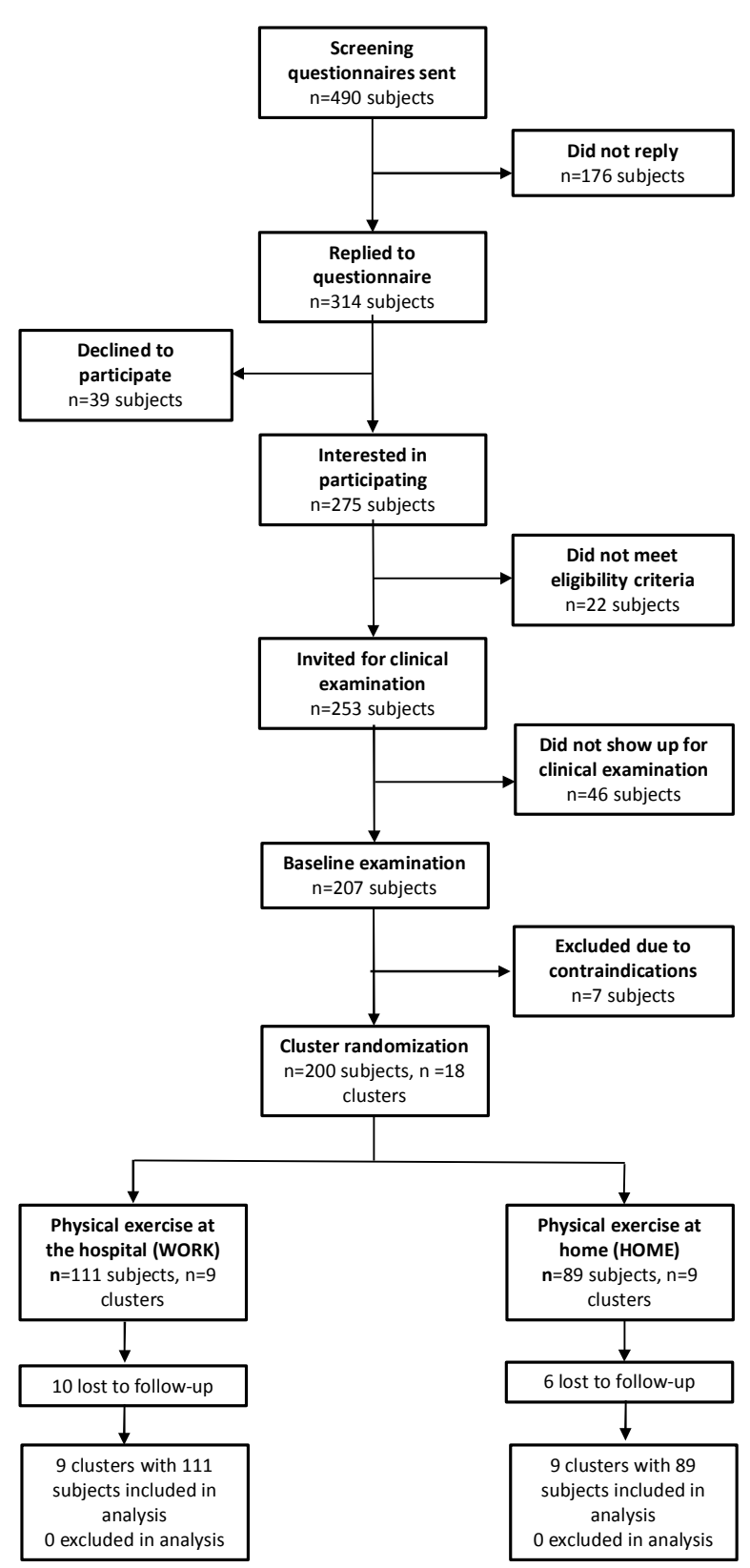

Figure 1. Participant recruitment flow-chart.

Cary, NC, USA) using the following procedure: (i) a dataset containing a column with 18 subsequent values of WORK, HOME, WORK, HOME etc. was made, (ii) another dataset containing a column with the 18 departments was assigned a random number using the ranuni function and sorted ascendingly, (iii) the two datasets were merged, (iv) the randomization information at the department level was then merged with the email information of the 200 participants. Subsequently, participants at each department and their management were informed by e-mail about group allocation. At follow-up (ie, post intervention: Dec 2013-Jan 2014) testing, all examiners of the strength measurement were blinded to the group allocation, and participants carefully instructed not to reveal their particular intervention group. Baseline characteristics and pain scores of the two intervention groups are illustrated in table 1.

Due to the nature of the intervention, it was not possible to blind participants, instructors, or coaches. As a consequence, the primary outcome - self-reported pain - is not blinded. Further, to avoid that potential placebo effects or outcome expectations would influence the results, participants were informed prior to the study that that neither of the intervention regimes were known to be superior to the other.

\section{Interventions}

Participants in each cluster were allocated to a 10-week intervention period receiving either physical exercise at work or physical exercise at home. Both training groups were encouraged to perform physical exercises for $5 \times 10$ minutes a week. The specific intervention protocols have been described in detail elsewhere (17) and are briefly summarized below.

\section{Workplace physical exercise (WORK)}

In brief, subjects randomized to physical exercise at their workplace (WORK) $(\mathrm{N}=111$ subjects, $\mathrm{N}=9$ clusters) performed supervised high-intensity strength training with elastic bands (Thera-Band ${ }^{\circledR}$ ) and kettlebells during working hours at the hospital. The training program consisted of ten exercises: (1) kettlebell deadlifts, (2) kettlebell swings, (3-6) squeeze, lateral raises, golf swings and woodchoppers using elastic tubing, (7-9) abdominal crunches, back extensions and squats using a swissball, and (10) lunges using elastic tubing. For each training session, the instructor chose 4-6 exercises that were performed as circuit training ie, quickly changing from one exercise to the next without rest. Progression in training intensity (loads) was ensured by using progressively more resistant elastic bands and heavier kettlebells throughout the 10-week intervention period, as supervised by the instructors. The exercises (woodchoppers, golf swings, lateral raises and lunges) were performed in a conventional manner using consecutive concentric and eccentric muscle contractions in a controlled way. The aim of the exercises was to increase muscle strength in the lower back, neck and shoulders and increase core (abdomen and lower back) stability.

All training sessions took place in designated rooms located close to the worksite departments. All sessions were supervised by a training instructor, who instructed the participants how to perform the exercises and helped with exercise adjustment when needed. 


\section{Coaching sessions}

The main objective of including coaching was to reinforce the effects of physical training. The coaching intervention involved groups of participants (typically 5-12) engaging in a supervised group dialogue sessions.

Each subject randomized to the WORK intervention was offered five coaching sessions of 30-45 minutes during working hours. The aims of the coaching sessions were to: (i) motivate workers to participate in the training sessions, (ii) help participants establish and maintain healthy lifestyles, and (iii) assist participants in encouraging their colleagues to attend their allocated intervention session (ie, physical training or coaching).

\section{Home-based physical exercise (HOME)}

Subjects randomized to home-based physical exercise (HOME) ( $\mathrm{N}=89$ subjects, $\mathrm{N}=9$ clusters) performed physical exercises during leisure time at home. At initiation of the study, participants received a bag containing (i) training equipment (easy, medium, and hard elastic tubing) and (ii) three posters visually demonstrating the exercises that should be performed for the shoulder-, abdominal- and back muscles, along with recommendations for training progression. Poster one (www.jobogkrop.dk/Ondt-i-muskler-og-led/Ondt-inakke-skulder-og-arm/ /media/Files/MSB/Shop/PDF/ Plakat-med-elastikoevelser-til-klinisk-personale.pdf) illustrated five exercises for the back, shoulder and arms using elastic tubing, especially designed for the clinical staff: (i) reverse flys, (ii) shoulder squeeze, (iii) shoulder external rotation, (iv) wrist extension and (v) wood choppers. Poster two (www.jobogkrop.dk/ Ondt-i-muskler-og-led/Ondt-i-ryggen/ /media/Files/ MSB/PDF/A2-Rygoevelser-v5-tryk.pdf) illustrated four exercises performed for the back, shoulder and arms using elastic tubing: (i) shoulder raises, (ii) shoulder squeezes, (iii) shoulder rotations and (iv) wrist extensions. Poster three (http://www.jobogkrop.dk/Ondti-muskler-og-led/Ondt-i-nakke-skulder-og-arm/ / media/Files/MSB/PDF/Exercises-with-elastic-band. pdf) illustrated four exercises for the back and abdominal muscles: (i) pelvic tilt, (ii) quadruped leg/arm raise, (iii) side planks and (iv) lean and turns. The selection of HOME exercises was based on previous research (1) and physiotherapeutic guidelines for reducing neck and shoulder and lower back pain and increasing neck, shoulder core muscle strength and stability.

\section{Ergonomic training and education}

During the intervention period, participants of both groups were offered courses (each of 1.5-3 hours) with ergonomic training and education in patient transfer and use of assistive devices. The courses were offered by the hospital's working environment department.

\section{Outcome measures}

Outcome measures were obtained by trained clinical examiners and viaquestionnaire survey at baseline and after the 10-week intervention period.

Primary outcome measure - pain intensity. Primary outcome was the change in average musculoskeletal pain intensity during the last week (average of low-back and neck/shoulder regions) from baseline to 10-week follow-up. The reason for using average neck/shoulder and low-back pain intensity was to ensure that the RCT only had a single primary outcome. Pain intensity was rated subjectively using a $0-10$ modified visual analogue scale, where 0 was used to indicate "no pain at all" while 10 indicated the "worst pain imaginable" $(18,19)$. The body regions were defined by drawings from the Nordic questionnaire (20). Because the neck and shoulder are located so close to each other, there is a high correlation between pain intensity in these areas. In the present study, the correlation coefficient (Pearson's r) between pain intensity in the neck and shoulder was 0.70 . By contrast the correlation coefficient between pain intensity in the low back and neck was 0.38 , and between the low back and shoulder was 0.33 . We therefore chose to consider the neck/shoulder as one region. The highest value of the neck and shoulder was therefore defined as neck/shoulder. However, the individual presentation of pain in the shoulder/neck and lower back is included as an exploratory analysis to show the differences in regional change in pain.

Secondary outcome - Back extensor muscle strength. Assessment of maximal muscle strength of the lower back muscles was a part of the physical examination at baseline and follow-up.

Maximal voluntary isometric contraction strength (MVC) was obtained for the lower-back extensor muscles using a custom-built dynamometer with a strain gauge load cell (KIS-2, 2 KN, Vishay Transducers Systems, Malvern, PA, USA). During the MVC maneuver, the subject was standing in an upright position wearing a vest with a steel rod horizontally placed at the upper part of the back, at the level of insertion of the deltoid muscle (17). At the distal end of the rod, a wire was horizontally connected to a strain-gauge dynamometer. The subject was facing the dynamometer with the pelvis positioned against a wooden plate (upper edge aligned with the subject's iliac crest) while performing a maximal back extensor contraction (3-s) on a cue given by the tester. Participants performed three attempts of each MVC, separated by a 30-second rest, and were 
instructed to apply force to the dynamometer as fast and forcefully as possible. The MVC trial with the highest peak force was selected for each individual for further statistical evaluation $(21,22)$. An identical positioning of the stabilizing plate was ensured at baseline and follow-up, respectively.

Self-rated use of analgesics (tertiary outcome measure). The number of days the participants used analgesics during the last week was assessed using a questionnaire at baseline and follow-up.

Subgroup with chronic musculoskeletal pain (pain-cases). For post hoc subgroup exploratory analysis of employees with chronic musculoskeletal pain, pain-cases were defined as those experiencing $\geq 3$ in pain intensity $(0-10$ scale) for $\geq 3$ months. Chronic pain can be defined as pain that lasts beyond the expected time of healing, thus three months seems like a realistic cut-off point. It should be noted that the cut-off of $\geq 3$ in pain intensity and duration of three months does not necessarily define a "real" pain case, but this is a realistic workplace definition used in other studies $(12,23)$.

\section{Perceived changes}

At follow-up, all participants completed a questionnaire describing perceived changes during the last ten weeks in terms of: (i) wellbeing, (ii) job satisfaction, (iii) desire to exercise, (iv) energy for family and friends, (v) motivation for healthier eating, (vi) socializing with colleagues, (vii) and awareness on proper use of assistive devices at the workplace, on a 3-point scale of "worsened", "unchanged", or "improved" (table 4) $(12,24)$.

\section{Sample size}

A priori power analysis based on previous measurements revealed that 64 participants in each group were needed to achieve $95 \%$ statistical power and SD of 1.5 , while a minimal relevant pre-to-post difference of pain intensity of 1 (25) was sufficient to test the null-hypothesis of equality $(\alpha=0.05)$. At an estimated $25 \%$ drop-out rate, group sizes were calculated to be at $\geq 80$. Due to an estimated inflation factor of 1.2 due to clustering effects, the estimated minimal group size was deemed to be 96 . The inflation factor used for the sample size calculations were based on the between- and within-cluster variance from a previous study (12). After the data were collected for the present study, we were also able to calculate actual the inflation factor; based on the change score in the primary outcome, the intracluster correlation coefficient for all clusters of the present study was 0.0457 and the average cluster size 11.1. Thus, the inflation factor was 1.46 , which is higher than anticipated prior to the study, but may be useful for sample size calculations in future studies with similar designs.

\section{Statistical analysis}

All statistical analyses were performed using the SAS statistical software for Windows. The change in pain (0-10 scale) was evaluated using a repeated-measures linear mixed model (Proc Mixed) with group, time, and group $\times$ time as independent variables. Participant nested within department was entered as random effect. Analyses were adjusted for age and pain intensity at baseline. All statistical analyses were performed in accordance with the intention-to-treat principle, ie, using the mixed procedure, which accounts for missing values (under the assumption that they are missing at random). An alpha level of 0.05 was accepted as statistically significant. Outcomes are reported as between-group differences and $95 \%$ confidence intervals $(95 \% \mathrm{CI})$ at follow-up. Finally, effect sizes were calculated as Cohen's d (26) based on average pain intensity (between-group differences divided by the pooled standard deviation at baseline).

\section{Results}

\section{Study population}

Table 1 shows baseline characteristics of the study participants. At baseline, age was slightly higher in the HOME compared with WORK group $(\mathrm{P}=0.05)$. We controlled for this difference in the statistical analyses by including age as a covariate. No other between-group differences were observed at baseline.

Sixteen participants did not complete the intervention; ten in the workplace group and six in the homebased group (cf. figure 1). These participants did not present for the follow-up examination, however their baseline values were included in the statistical analyses. In the WORK group, six participants dropped out due to job transfer, and four dropped out due to lack of time to do the exercises as they were assigned only night shifts. In the HOME group, two participants dropped out due to job transfer, three due to illness unrelated to the exercise program, and one participant were on sick leave during the intervention.

The WORK and HOME group on average performed 2.2 (SD 1.1) and 1.0 (SD 1.2) of the 5 offered training sessions per week, corresponding to a training adherence of $45 \%$ and $21 \%$, respectively, which differed between groups $(\mathrm{P}<0.001)$. In addition, WORK participants attended, on average, 2.1 coaching sessions during the 10 -week intervention period. 
Table 1. Characteristics of study and pain-case participants. [HOME=home-based physical exercise; WORK=work-based physical exercise; pHOME=pain cases assigned to home-based physical exercise; pWORK=pain cases assigned to work-based physical exercise; $\mathrm{SD}=$ standard deviation].

\begin{tabular}{|c|c|c|c|c|c|c|c|c|}
\hline & \multicolumn{2}{|c|}{ HOME } & \multicolumn{2}{|c|}{ WORK } & \multicolumn{2}{|c|}{ pHOME } & \multicolumn{2}{|c|}{ pWORK } \\
\hline & Mean & SD & Mean & SD & Mean & SD & Mean & SD \\
\hline Number & 89 & & 111 & & 45 & & 52 & \\
\hline Age (years) & 44 & 10 & $40^{a}$ & 12 & 45 & 11 & $40^{a}$ & 12 \\
\hline Height $(\mathrm{cm})$ & 168.0 & 7.2 & 168.4 & 6.2 & 167.2 & 6.8 & 167.8 & 6.7 \\
\hline Weight $(\mathrm{kg})$ & 68.9 & 12.2 & 67.5 & 12.1 & 68.8 & 12.4 & 68.3 & 11.0 \\
\hline Body mass index $\left(\mathrm{kg} / \mathrm{m}^{2}\right)$ & 24.4 & 4.0 & 23.8 & 3.8 & 24.6 & 4.0 & 24.3 & 4.1 \\
\hline $\begin{array}{l}\text { Average pain intensity in the low back, neck, and shoulders } \\
\text { during the last week (scale } 0-10 \text { ) }\end{array}$ & 3.1 & 0.1 & 3.0 & 0.1 & 4.9 & 0.2 & 4.7 & 0.2 \\
\hline Low-back pain intensity during the last week (scale 0-10) & 2.9 & 0.1 & 2.9 & 0.1 & 4.6 & 0.3 & 4.5 & 0.2 \\
\hline Neck/shoulder pain intensity during the last week (scale $0-10$ ) & 2.8 & 0.2 & 2.6 & 0.1 & 4.3 & 0.3 & 4.1 & 0.2 \\
\hline Weekly intake of analgesics & 0.78 & 0.1 & 0.87 & 0.1 & 1.09 & 0.2 & 1.21 & 0.2 \\
\hline Back extensor strength (Nm) & 147.5 & 20.9 & 146.9 & 19.9 & 146.6 & 14.2 & 146.4 & 14.3 \\
\hline
\end{tabular}

a Difference between groups at baseline, $\mathrm{P}<0.05$.

Pain, muscle strength, and use of analgesics

A priori hypothesis testing showed a groupxtime interaction for pain intensity $(\mathrm{P}=0.01)$. Compared with HOME, average pain intensity decreased [-0.7 (95\% CI - 1.0 to -0.3 )] in the WORK group (table 2). In an exploratory analysis, a similar pattern was observed for regional lower-back pain $(\mathrm{P}=0.02)$ whereas no change was seen for the neck/shoulder $(\mathrm{P}=0.09)$ pain intensity. Effect size for the change in pain was 0.31 , which was categorized as small (from 0.20 to 0.50 ).

A group $\times$ time interaction was also observed for lower-back muscle strength $(\mathrm{P}<0.001)$. Compared to HOME, lower-back muscle strength increased to a greater extent in the WORK group (table 2).

A group xtime interaction was found for weekly intake of analgesics (days during the last week) $(\mathrm{P}=0.005)$. Compared with HOME, the intake of analgesics was reduced to a greater extent in WORK group [-0.4 (-0.7 to -0.2$)$ days per week], table 2 .

\section{Exploratory analyses of pain cases}

Table 1 shows baseline characteristics of the pain cases identified in the two intervention groups. There was a significant group $\times$ time interaction for the change from baseline to 10 -week follow-up in pain intensity $(\mathrm{P}=0.01)$, use of analgesics $(\mathrm{P}=0.03)$, and muscle strength ( $\mathrm{P}=0.009)$ (table 2). Effect size (Cohen's d) for the change in pain was 0.63 , which was categorized as moderate $(0.50-0.80)$. Of the WORK participants, $78 \%$ experienced some or much improvement of pain, while similar changes were seen in $42 \%$ of the pain-case participants assigned to $\operatorname{HOME}(\mathrm{P}=0.006)$ (table 3$)$.

\section{Perceived changes at follow-up}

Compared with HOME, a greater proportion of WORK participants reported improved well-being and greater increases in job satisfaction, desire to exercise, energy for family and friends, while also more motivated to eat better and socialize more with their colleagues at 10 -week follow-up $(\mathrm{P}<0.05)$ (table 4$)$. No differences were observed in the awareness on proper use of assistive devices at the work place $(\mathrm{P}=0.24)$ (table 4$)$.

\section{Discussion}

The present cluster RCT showed significant improvements in musculoskeletal pain intensity, muscle strength, and use of analgesics among female healthcare workers in response to ten weeks of exercise at the workplace compared to home-based exercise.

Participants allocated to workplace exercise experienced a reduction in average pain intensity of 0.8 points corresponding to an effect size of 0.31 from baseline to follow-up. A small, but statistically non-significant reduction in pain was also seen following ten weeks of home-based exercise. Previous studies have reported comparable reductions in neck/shoulder or back pain in response to 10-20 weeks of strength training at the workplace using elastic rubber bands (19), kettlebells (27) or free weight exercises $(12,21,28)$ when implemented for laboratory technicians and office workers. However, these findings may not be directly transferable to healthcare workers who typically are engaged in much heavier load handling (patient ambulation). Studies examining the prevalence of low back, neck and/ or shoulder pain after workplace exercise interventions among healthcare workers are limited and contradictory (14). Particularly, exercise-based interventions for treatment of low-back pain among healthcare workers represent a great challenge (29-31), Yet, the present study was successful in demonstrating that supervised 
Table 2. Changes in average pain intensity (low back and neck/shoulder), use of analgesics and maximal muscle strength from baseline to 10-week follow-up. [HOME=home-based physical exercise; WORK=work-based physical exercise; pHOME=pain cases assigned to homebased physical exercise; pWORK=pain cases assigned to work-based physical exercise; $95 \% \mathrm{Cl}=95 \%$ confidence interval]

\begin{tabular}{|c|c|c|c|c|c|c|c|c|c|c|c|c|c|c|}
\hline & \multicolumn{8}{|c|}{$\begin{array}{c}\text { Difference from baseline } \\
\text { to follow-up }\end{array}$} & \multirow[t]{3}{*}{ P-value } & \multicolumn{4}{|c|}{$\begin{array}{l}\text { Between group difference } \\
\text { at follow-up }\end{array}$} & \multirow[t]{3}{*}{ P-value } \\
\hline & \multicolumn{2}{|c|}{ WORK } & \multicolumn{2}{|c|}{ HOME } & \multicolumn{2}{|c|}{ pWORK } & \multicolumn{2}{|c|}{ pHOME } & & \multicolumn{4}{|c|}{ WORK vs HOME pWORK vs pHOME } & \\
\hline & Mean & $95 \% \mathrm{Cl}$ & Mean & $95 \% \mathrm{Cl}$ & Mean & $95 \% \mathrm{Cl}$ & Mean & $95 \% \mathrm{Cl}$ & & Mean & $95 \% \mathrm{Cl}$ & Mean & $95 \% \mathrm{Cl}$ & \\
\hline Pain intensity $(0-10)$ & -0.8 & $-1.1--0.5$ & -0.2 & $-0.6-0.1$ & -1.7 & $-2.2-1.2$ & -0.8 & $-1.3-0.2$ & $<0.0001$ & -0.7 & $-1.0--0.3$ & -1.0 & $-1.5--0.5$ & $<0.0003$ \\
\hline Use of & -0.3 & & 0.3 & & -0.4 & $-0.8-0.1$ & 0.4 & $-0.1-0.9$ & $<0.01$ & -0.4 & $-0.7--0.2$ & -0.6 & $1--0.1$ & 0.013 \\
\hline Back extensor strength (Nm) & 12.7 & $10.6-14.9$ & 6.7 & $4.7-9.1$ & 2.9 & $-1.0-6.8$ & -4.8 & $-0.4-9.2$ & $<0.001$ & $1 \quad 5.5$ & $2.0-9.0$ & 7.6 & $1.3-13.9$ & 0.018 \\
\hline
\end{tabular}

Table 3. Percentage of pain-case participants showing improvement, no change or worsening of perceived pain intensity in the lower back, neck and shoulder regions from baseline to 10-weeks follow-up $(\mathrm{P}<0.01)$. Cut-off points were: $<25 \%=$ no change; $\geq 25-$ $<50 \%=$ some change; $\geq 50 \%=$ much change. [pHOME=pain cases assigned to home-based physical exercise; pWORK=pain cases assigned to work-based physical exercise]

\begin{tabular}{lcc}
\hline & \multicolumn{2}{c}{$\begin{array}{c}\text { Average pain intensity for lower back, } \\
\text { neck and shoulder (\%) }\end{array}$} \\
\cline { 2 - 3 } & pWORK & pHOME \\
\cline { 2 - 3 } Much improvement & 35.6 & 25.6 \\
Some improvement & 42.2 & 16.3 \\
No change & 11.1 & 34.9 \\
Some worsening & 11.1 & 20.9 \\
Much worsening & 0.0 & 2.3 \\
\hline
\end{tabular}

Table 4. Subjective outcome parameters (worsened/unchanged/ improved) related to self-perceived physical and social characteristics. Values denote percentages of participants. [HOME=Homebased physical exercise; WORK=Work based physical exercise]

\begin{tabular}{|c|c|c|c|c|}
\hline \multirow[t]{2}{*}{$\begin{array}{l}\text { Outcome according } \\
\text { to group }\end{array}$} & \multicolumn{3}{|c|}{$\begin{array}{l}\text { Percentage of } \\
\text { participants }\end{array}$} & \multirow{2}{*}{$\begin{array}{l}\text { Fischer's } \\
\text { exact test } \\
\text { P-value }\end{array}$} \\
\hline & Worsened & Unchanged & Improved & \\
\hline \multicolumn{5}{|l|}{ Wellbeing } \\
\hline WORK & 0 & 49 & 51 & \multirow[t]{2}{*}{$<0.0001$} \\
\hline HOME & 4 & 89 & 7 & \\
\hline \multicolumn{5}{|l|}{ Job satisfaction } \\
\hline WORK & 4 & 64 & 32 & \multirow[t]{2}{*}{$<0.0001$} \\
\hline HOME & 5 & 90 & 5 & \\
\hline \multicolumn{5}{|l|}{ Desire to exercise } \\
\hline WORK & 1 & 40 & 59 & \multirow[t]{2}{*}{$<0.0001$} \\
\hline HOME & 4 & 78 & 19 & \\
\hline \multicolumn{5}{|c|}{ Energy for family, friends } \\
\hline \multicolumn{5}{|c|}{ or other things in their } \\
\hline WORK & 1 & 78 & 21 & \multirow[t]{2}{*}{$<0.0001$} \\
\hline HOME & 5 & 93 & 2 & \\
\hline \multicolumn{5}{|c|}{ Motivated to eat healthier } \\
\hline WORK & 0 & 69 & 31 & \multirow[t]{2}{*}{$<0.01$} \\
\hline HOME & 2 & 83 & 15 & \\
\hline \multicolumn{5}{|l|}{$\begin{array}{l}\text { Socializing with } \\
\text { colleagues }\end{array}$} \\
\hline WORK & 0 & 38 & 62 & \multirow[t]{2}{*}{0.038} \\
\hline HOME & 4 & 93 & 4 & \\
\hline \multicolumn{5}{|c|}{$\begin{array}{l}\text { Awareness on proper use } \\
\text { of assistive devices }\end{array}$} \\
\hline WORK & 0 & 84 & 16 & \multirow[t]{2}{*}{0.24} \\
\hline HOME & 0 & 90 & 10 & \\
\hline
\end{tabular}

workplace-based resistance exercise intervention may have a rehabilitative effect on low-back pain comparable with that seen for neck/shoulder pain.

Generally, the effect of exercise intervention seems more effective for chronic than acute pain $(12,32-36)$. As the present participants were somewhat heterogeneous in terms of pain duration and intensity, this may partly explain the observed small effect size and moderate within-group change in pain intensity ( -0.8 points) compared with the effect of exercise intervention reported among chronic pain cases $(21,23)$. Noteworthy, among pain cases, we observed a higher but moderate effect size of 0.63 and a post-intervention between-group difference of 1 point in pain intensity in the subgroup analysis of pain-cases. The possibility exists that the similar trends of the two exercise interventions may have diminished the observed effect size between groups. Yet, almost $80 \%$ of the pain cases allocated to the WORK group responded with a reduction in pain compared to $42 \%$ in HOME. Nevertheless, these observations highlight the promising effect of performing physical exercise intervention at the workplace as a countermeasure against chronic as well as non-chronic pain cases.

Higher adherence in the WORK compared with HOME group may explain our results. The WORK group trained 2.2 times per week, leading to significant reductions in pain, weekly intake of analgesics, and increased muscle strength, whereas the HOME group trained on average only once per week. The use of instructors throughout the intervention may have increased adherence as supervised intervention is known to enhance exercise adherence (15). In addition, the provision of five coaching sessions for the workplace group may have increased their motivation for attending the daily training and thus contributed to increase training adherence. Still, the average adherence of $45 \%$ (2.2 of 5 possible weekly sessions) within the WORK group was not particularly high, but probably what is realistic in a hospital setting. Nevertheless, a lot of the departments were understaffed during the period of intervention and it seemed unrealistic that all subjects could participate in every single training session planned. However, given 
that previous workplace interventions have shown effective reductions in musculoskeletal pain after as little as 20 minutes or 2 sessions per week $(12,33,34)$, we sought to counteract low adherence by offering 5 weekly training sessions during working hours. On the other hand, exercising only 10 minutes once a week, as seen in the home-based training group, seems to be insufficient for significantly reducing musculoskeletal pain.

The weekly intake of analgesics was reduced from 0.87 to 0.61 days per week following participation in the WORK group whereas the HOME intervention was associated with an increased weekly intake of about 0.25 days per week, resulting in a significant between-group difference of 0.4 days per week following the period of intervention. The increase in use of analgesics among HOME participants may be explained by seasonal variations, ie, the baseline questionnaire was completed around September and the follow-up questionnaire during the colder period around December (winter). Previous studies have reported contrasting findings on the effects of exercise on analgesic self-administration $(29,37,38)$. However, the present reduction in the use of analgesics was positively associated with the decrease in pain seen in the WORK group (spearman's $r=0.28$, $\mathrm{P}<0.01$ ). Noteworthy, the present data suggest that treatment for long-term pain relief by workplace physical exercise may yield symptomatic benefits without leading to an increased use of analgesics, which potentially can lead to adverse events.

The positive perceived changes registered at followup support the changes in pain intensity and satisfaction with the intervention observed among participants subjected to workplace training. Thus, WORK participants reported increased wellbeing, enhanced job satisfaction, an increased desire to exercise, and more energy for family and friends. These findings should be considered in a biopsychosocial context. The biopsychosocial model focuses on the interaction between biological, psychological, and social factors in the neurological perception of pain (39). Hence, besides the physiological training effects, the fact that WORK participants trained in groups at the department may have had greater impact on the social relationship among colleagues and the psychological wellbeing of the individual. This was further supported by a higher proportion of WORK participants experiencing an increase in the amount of socializing with colleagues compared to those in the HOME group. Finally, as both intervention groups received an identical education in the use of assistive devices at the work place, it was not surprising to observe similar perceived changes in awareness on proper use of assistive devices.

The WORK group was more effective than the HOME group in increasing muscle strength of the lower back muscles. However, both interventions induced significant within-group changes of $8.7 \%$ versus $4.5 \%$ in the WORK and HOME group, respectively. An increase in physical capacity would likely lower relative exposure during work, which may indirectly have contributed to the observed improvements in pain (13).

Furthermore, although both intervention groups performed strengthening exercises for the neck, shoulder, and lower-back regions, not all exercises were comparable. Especially, as reported by Jay et al (27), the provision of ballistic kettlebell swings in the WORK group may have contributed to the larger reduction in lower back pain and higher increase in lower-back muscle strength observed in the WORK versus HOME group. The reason for excluding kettlebell training and coaching sessions in the HOME group was to compare the effect of two contrasting interventions: one lowcost intervention that required as little equipment and instruction as possible with an intervention that invests in instructors, equipment, coaches, and working hours. Accordingly, two different "real-life" packages were compared as opposed to single elements within each intervention. Furthermore, the kettlebell swing can be technically challenging to perform and may lead to injuries without qualified instruction (40) and for safety reasons we therefore chose not to include this type of training in the HOME group. It may be argued that investing additional resources (ie, guidance and encouragement) in home-based training may have increased training adherence and thus potentially reduced the average pain. However, increased investment in the HOME group would compromise the study design: comparing a low-cost intervention versus an intervention that invests in instructors, equipment, coaches, and working hours.

\section{Strengths and limitations}

The present study has both strengths and limitations. The cluster RCT design with concealed allocation and blinded clinical examiners protects against systematic bias. A limitation is that the statistical model assumes that missing values are missing at random, and we do not know whether this is the case. However, the low loss of participants at follow-up and inclusion of drop-outs in the statistical analysis allowed us to test the actual effect of the interventions using the intention-to-treat principle. Thus, whether the few missing values were missing at random or not is unlikely to markedly influence the outcome. A general weakness of behavioral interventions is that blinding of participants and those administrating the intervention is not possible. Accordingly, perceived pain may be influenced by outcome expectations. However, to minimize this type of bias we included two active intervention groups rather than comparing treatment with a passive waiting list group $(40,41)$.

According to our power calculations the minimal 
relevant pre-to-post difference of average pain intensity was set to 1 . This was chosen based on previous studies using subject with pain $(23,42)$. In the present study we have a mixture of people with and without pain. As far as we know the minimal relevant difference for pain prevention is unknown. Thus, it may or may not be that 0.7 is relevant in this population. Nevertheless, the flooring effect is a limitation in regard to using 1 as the minimal relevant difference.

Furthermore, the present pain cases are a subgroup within each intervention group and because we did not stratify randomization for pain / non-pain cases these results should be interpreted with caution. In addition, the follow-up questionnaire of table 4 are not validated and should therefore be interpreted with caution.

\section{Concluding remarks}

The present data demonstrate that performing physical exercise at the workplace is more effective than home-based exercise in reducing musculoskeletal pain, increasing muscle strength, and reducing weekly intake of analgesics among female healthcare workers.

\section{Acknowledgments}

The authors thank Anne Zöega Kristensen, Jørgen Skotte, and Klaus Hansen from the National Research Centre for the Working Environment for valuable technical assistance and support. Further thanks goes to Reinhard Stelter and Ebbe Lavendt from the Coaching Psychology Unit, University of Copenhagen.

This study was supported by a grant from the Danish Parliament (SATS 2004) and the Danish Working Environment Research Fund (Grant no. 48-2010-03).

\section{Competing interests}

The authors of the article declare that they have no conflict of interest what so ever. Further, the research has not received any funding or grant from any commercial source.

\section{References}

1. McDonald M, DiBonaventura M daCosta, Ullman S. Musculoskeletal pain in the workforce: the effects of back, arthritis, and fibromyalgia pain on quality of life and work productivity. J Occup Environ Med. 2011;53(7):765-70.

2. Andersen LL, Clausen T, Burr H, Holtermann A. Threshold of musculoskeletal pain intensity for increased risk of longterm sickness absence among female healthcare workers in eldercare. PLoS ONE. 2012;7(7):e41287. http://dx.doi. org/10.1371/journal.pone.0041287.

3. Holtermann A, Jørgensen MB, Gram B, Christensen JR, Faber A, Overgaard K, Ektor-Andersen J, Mortensen OS, Sjøgaard G, Søgaard K. Worksite interventions for preventing physical deterioration among employees in job-groups with high physical work demands: background, design and conceptual model of FINALE. BMC Public Health. 2010;10:120. http:// dx.doi.org/10.1186/1471-2458-10-120.

4. Lund T, Labriola M, Christensen KB, Bultmann U, Villadsen E. Physical work environment risk factors for long term sickness absence: prospective findings among a cohort of 5357 employees in Denmark. BMJ. 2006;332(7539):449-52.

5. Skotte JH, Essendrop M, Hansen AF, Schibye B. A dynamic 3D biomechanical evaluation of the load on the low back during different patient-handling tasks. J Biomech. 2002;35(10):1357-66.

6. Andersen LL, Clausen T, Mortensen OS, Burr H, Holtermann A. A prospective cohort study on musculoskeletal risk factors for long-term sickness absence among healthcare workers in eldercare. International Archives of Occupational and Environmental Health [Internet]. 11 October 2011 [cited 13. November 2011]; Available from: http://www.ncbi.nlm.nih. gov/pubmed/21986907.

7. Simoens S, Villeneuve M, Hurst J. Tackling Nurse Shortages in OECD Countries. OECD Health Working Papers. 2005;19.

8. Andersen LL, Burdorf A, Fallentin N, Persson R, Jakobsen MD, Mortensen OS, et al. Patient transfers and assistive devices: prospective cohort study on the risk for occupational back injury among healthcare workers. Scand J Work Environ Health. 2014 Jan;40(1):74-81. http://dx.doi.org/10.5271/ sjweh.3382.

9. Burdorf A, Koppelaar E, Evanoff B. Assessment of the impact of lifting device use on low back pain and musculoskeletal injury claims among nurses. Occup Environ Med. 2013;70(7):491-7. http://dx.doi.org/10.1136/ oemed-2012-101210.

10. Verhagen AP, Bierma-Zeinstra SMA, Burdorf A, Stynes SM, de Vet HCW, Koes BW. Conservative interventions for treating work-related complaints of the arm, neck or shoulder in adults. Cochrane Database Syst Rev. 2013;12:CD008742.

11. Andersen LL, Jakobsen MD, Pedersen MT, Mortensen OS, Sjøgaard G, Zebis MK. Effect of specific resistance training on forearm pain and work disability in industrial technicians: cluster randomised controlled trial. BMJ Open. 2012;2(1):e000412. http://dx.doi.org/10.1136/ bmjopen-2011-000412.

12. Zebis MK, Andersen LL, Pedersen MT, Mortensen P, Andersen $\mathrm{CH}$, Pedersen MM, Boysen M, Roessler KK, Hannerz $\mathrm{H}$, Mortensen OS, Sjøgaard G. Implementation of neck/ shoulder exercises for pain relief among industrial workers: a randomized controlled trial. BMC Musculoskelet Disord. 2011;12:205. http://dx.doi.org/10.1186/1471-2474-12-205. 
13. Andersen LL, Andersen CH, Zebis MK, Nielsen PK, Sogaard K, Sjøgaard G. Effect of physical training on function of chronically painful muscles: a randomized controlled trial. J ApplPhysiol. 2008;105(6):1796-801. http://dx.doi. org/10.1152/japplphysiol.91057.2008.

14. Bigos SJ, Holland J, Holland C, Webster JS, Battie M, Malmgren JA. High-quality controlled trials on preventing episodes of back problems: systematic literature review in working-age adults. Spine J. 2009;9(2):147-68. http://dx.doi. org/10.1016/j.spinee.2008.11.001.

15. Jordan JL, Holden MA, Mason EE, Foster NE. Interventions to improve adherence to exercise for chronic musculoskeletal pain in adults. Cochrane Database Syst Rev. 2010;(1):CD005956.

16. Karlsson L, Takala E-P, Gerdle B, Larsson B. Evaluation of pain and function after two home exercise programs in a clinical trial on women with chronic neck pain with special emphasises on completers and responders. BMC Musculoskelet Disord. 2014;15(1):6. http://dx.doi. org/10.1186/1471-2474-15-6.

17. Jakobsen MD, Sundstrup E, Brandt M, Kristensen AZ, Jay K, Stelter R, Lavendt E, Aagaard P, Andersen LL. Effect of workplace- versus home-based physical exercise on pain in healthcare workers: study protocol for a single blinded cluster randomized controlled trial. BMC Musculoskelet Disord. 2014;15(1):119. http://dx.doi.org/10.1186/1471-2474-15119 .

18. Pincus T, Bergman M, Sokka T, Roth J, Swearingen C, Yazici $\mathrm{Y}$. Visual analog scales in formats other than a 10 centimeter horizontal line to assess pain and other clinical data. J Rheumatol. 2008;35(8):1550-8.

19. Andersen LL, Saervoll CA, Mortensen OS, Poulsen OM, Hannerz H, Zebis MK. Effectiveness of small daily amounts of progressive resistance training for frequent neck/shoulder pain: randomised controlled trial. Pain. 2011;152(2):440-6. http://dx.doi.org/10.1016/j.pain.2010.11.016.

20. Kuorinka I, Jonsson B, Kilbom A, Vinterberg H, BieringSørensen F, Andersson G, Jørgensen K. Standardised Nordic questionnaires for the analysis of musculoskeletal symptoms. Appl Ergon. 1987;18(3):233-7. http://dx.doi. org/10.1016/0003-6870(87)90010-X.

21. Andersen LL, Kjaer M, Søgaard K, Hansen L, Kryger AI, Sjøgaard G. Effect of two contrasting types of physical exercise on chronic neck muscle pain. Arthritis Rheum. 2008;59(1):84-91.

22. Jakobsen MD, Sundstrup E, Andersen CH, Zebis MK, Mortensen P, Andersen LL. Evaluation of muscle activity during a standardized shoulder resistance training bout in novice individuals. Journal of Strength and Conditioning Research / National Strength \& Conditioning Association [Internet]. 5. November 2011 [cited 11 November 2011]; Available from: http://www.ncbi.nlm.nih.gov/pubmed/22067242.

23. Sundstrup E, Jakobsen MD, Andersen CH, Jay K, Persson R, Aagaard P, Andersen LL. Effect of two contrasting interventions on upper limb chronic pain and disability: a randomized controlled trial. Pain Physician. 2014;17(2):14554.
24. Jay K, Jakobsen MD, Sundstrup E, Skotte JH, Jørgensen MB, Andersen CH, Pedersen MT, Andersen LL. Effects of kettlebell training on postural coordination and jump performance: A randomized controlled trial. J Strength Cond Res. 2013 May;27(5):1202-9. http://dx.doi.org/10.1519/ JSC.0b013e318267a1aa.

25. Dworkin RH, Turk DC, McDermott MP, Peirce-Sandner S, Burke LB, Cowan P, et al. Interpreting the clinical importance of group differences in chronic pain clinical trials: IMMPACT recommendations. Pain. 2009;146(3):238-44. http://dx.doi. org/10.1016/j.pain.2009.08.019.

26. Cohen, J. Statistical Poer Analysis for the Behavioral Sciences. Lawrence Erlbaum Associates; 1988.

27. Jay K, Frisch D, Hansen K, Zebis MK, Andersen CH, Mortensen OS, Andersen LL. Kettlebell training for musculoskeletal and cardiovascular health: a randomized controlled trial. Scand J Work Environ Health. 2011;37(3):196-203. http://dx.doi. org/10.5271/sjweh.3136.

28. Ylinen J, Takala E-P, Nykänen M, Häkkinen A, Mälkiä E, Pohjolainen T, Karppi SL, Kautianen H, Airaksinen O. Active neck muscle training in the treatment of chronic neck pain in women: a randomized controlled trial. JAMA. 2003;289(19):2509-16. http://dx.doi.org/10.1001/ jama.289.19.2509.

29. Linton SJ, Bradley LA, Jensen I, Spangfort E, Sundell L. The secondary prevention of low back pain: a controlled study with follow-up. Pain. 1989;36(2):197-207.

30. Horneij E, Hemborg B, Jensen I, Ekdahl C. No significant differences between intervention programmes on neck, shoulder and low back pain: a prospective randomized study among home-care personnel. J Rehabil Med. 2001;33(4):1706.

31. Gerdle B, Brulin C, Elert J, Eliasson P, Granlund B. Effect of a general fitness program on musculoskeletal symptoms, clinical status, physiological capacity, and perceived work environment among home care service personnel. J Occup Rehabil. 1995;5(1):1-16.

32. Van Tulder M, Malmivaara A, Esmail R, Koes B. Exercise therapy for low back pain: a systematic review within the framework of the cochrane collaboration back review group. Spine. 2000;25(21):2784-96.

33. Gram B, Andersen C, Zebis MK, Bredahl T, Pedersen MT, Mortensen OS, Jensen RH, Andersen LL, Sjøgaard G. Effect of training supervision on effectiveness of strength training for reducing neck/shoulder pain and headache in office workers: cluster randomized controlled trial. Biomed Res Int. 2014;2014:693013. http://dx.doi.org/10.1155/2014/693013.

34. Andersen $\mathrm{CH}$, Andersen LL, Gram B, Pedersen MT, Mortensen OS, Zebis MK, Sjøgaard G. Influence of frequency and duration of strength training for effective management of neck and shoulder pain: a randomised controlled trial. British Journal of Sports Medicine [Internet]. 29 June 2012 [cited 10 August 2012]; Available from: http://bjsm.bmj.com/cgi/ doi/10.1136/bjsports-2011-090813.

35. Andersen LL, Jorgensen MB, Blangsted AK, Pedersen MT, 
Hansen EA, Sjogaard G. A randomized controlled intervention trial to relieve and prevent neck/shoulder pain. Med SciSports Exerc. 2008;40(6):983-90.

36. Blangsted AK, Søgaard K, Hansen EA, Hannerz H, Sjøgaard G. One-year randomized controlled trial with different physical-activity programs to reduce musculoskeletal symptoms in the neck and shoulders among office workers. Scand J Work Environ Health. 2008;34(1):55-65. http:// dx.doi.org/10.5271/sjweh.1192.

37. Van Baar ME, Dekker J, Oostendorp RA, Bijl D, Voorn TB, Lemmens JA, Bijlsma JW. The effectiveness of exercise therapy in patients with osteoarthritis of the hip or knee: a randomized clinical trial. J Rheumatol. 1998;25(12):2432-9.

38. Bunketorp L, Lindh M, Carlsson J, Stener-Victorin E. The effectiveness of a supervised physical training model tailored to the individual needs of patients with whiplash-associated disorders--a randomized controlled trial. Clin Rehabil. 2006;20(3):201-17. http://dx.doi. org/10.1191/0269215506cr934oa.
39. Gatchel RJ, Peng YB, Peters ML, Fuchs PN, Turk DC. The biopsychosocial approach to chronic pain: scientific advances and future directions. Psychol Bull. 2007 Jul;133(4):581-624. http://dx.doi.org/10.1037/0033-2909.133.4.581

40. Jonen W, Netterville JT. Kettlebell Safety: A Periodized Program Using the Clean and Jerk and the Snatch. Strength and Conditioning Journal. 2014;36(2):1-10. http://dx.doi. org/10.1519/SSC.0000000000000022.

41. Andersen JH, Mikkelsen S. The placebo effect revisited. Scand J Work Environ Health. 2012;38(2):182. http://dx.doi. org/10.5271/sjweh.3266.

42. Andersen LL. The placebo effect revisited - author response Scand J Work Environ Health. 2012;38(2):183-4. http:// dx.doi.org/10.5271/sjweh.3270.

Received for publication: 9 June 2014 